\title{
Behavioural repertoire of termites in corpse management: A comparison between one-piece and multiple-pieces nesting termite species
}

\author{
Luiza Helena Bueno da Silva, Ana Maria Costa-Leonardo* \\ Laboratório de Cupins, Departamento de Biologia, Instituto de Biociências, UNESP - Univ Estadual Paulista, Av. 24A, 1515, CEP: 13506-900 Rio Claro, SP, Brazil
}

\section{A R T I C L E I N F O}

\section{Keywords:}

Cannibalism

Cornitermes cumulans

Corpse-burying behaviour

Cryptotermes brevis

Isoptera

Undertaking behaviour

\begin{abstract}
A B S T R A C T
Corpse disposal is an essential adaptation to social life. This behaviour promotes nest hygiene and prevents the spread of pathogens in the colony of social insects. The current study verified the corpse management in two termite families towards cadavers of different origins. We carried out bioassays with subcolonies of Cryptotermes brevis and colonies of Cornitermes cumulans, in which corpses of termite workers from the same colony, from another colony and from another species were introduced. The results showed that $C$. brevis consumed the corpses regardless of their origin, but they avoided the chitinous parts of the head. In this species, consumption of dead individuals, besides performing a hygienic function, seems to be a strategy for nitrogen and water acquisition. In the $C$. cumulans species, interspecific and intercolonial corpses were covered with soil and faeces after being groomed. Nestmate corpses were entombed, transported to the nest or ignored after being submitted to grooming. Our findings indicate that a one-piece nesting termite, as $C$. brevis, exhibited a simplified corpse management repertoire in relation to that performed by $C$. cumulans, a multiple-piece nesting species, whose approach was more complex and diverse. Behavioural responses are associated with the nesting of the species.
\end{abstract}

\section{Introduction}

The presence of dead individuals inside social insect nests can present a risk of contamination with pathogens, damaging the integrity of the colony (Cremer et al., 2007). Corpse management is considered to be an important characteristic of adaptation to social living and, to prevent prolonged contact with corpses, the social insects perform different undertaking strategies (López-Riquelme and Fanjul-Moles, 2013). These strategies consist of a complex and sophisticated sequence of behavioural patterns elicited by the presence of cadavers of different origins, ages and infection status (Sun and Zhou, 2013). The behavioural responses for disposing of corpses vary among the social insect groups and are dependent on the feeding habit and nest ecology (Neoh et al., 2012). Honey bees remove nestmate corpses from their nest, while ants remove cadavers to the exterior of the nest or to special chambers (Visscher, 1983; Wilson et al., 1958). In some ant species, however, both burial and cannibalism have also been documented (Driessen et al., 1984; Renucci et al., 2011). Likewise, termites perform varied responses that include avoiding contact with the corpse, cannibalism, removal and burial (Sun and Zhou, 2013).

Social insect colony members must be able to distinguish between dead and living individuals before initiating corpse management. Death recognition depends on varied cadaver cues, which can be tactile and, or chemical (Sun and Zhou, 2013). Two main hypotheses about the recognition through chemical signals are accepted. One of them is that death recognition occurs due to the accumulation of postmortem substances. In several insects, the accumulation of unsaturated acids, e.g. oleic acid and linoleic acid, elicits undertaking responses. According to Wilson (1985), two species of ant, Pogonomyrmex badius and Solenopsis saevissima, recognise dead individuals due to the emission of fatty acids, especially oleic acid. Studies with other species of ant, as well as bee and termite, corroborate the hypothesis of "fatty acid as warning of death" (Haskins and Haskins, 1974; Howard and Tschinkel, 1976; Ulyshen and Shelton, 2012; Visscher, 1983; Yao et al., 2009). The second hypothesis is that corpse management is triggered by a reduction of vital chemical signs present in the cadaver cuticle, such as the disappearance of dolichodial and iridomyrmecin on the corpse cuticle of the ant Linepithema humile (Choe et al., 2009).

One of the termite species studied is Cryptotermes brevis (Walker, 1853), whose origin is probably Peru-Chile (Scheffrahn et al., 2009), that is a drywood termite belonging to the Kalotermitidae family. This species is a one-piece nesting termite, i.e., it nests in the piece of wood that serves as food resource (Korb, 2005). The colonies of $C$. brevis live in woods with humidity below $30 \%$ and, therefore, these termites obtain humidity from their own food and conserve it through the production of dry faeces (Brazolini et al., 2001)

\footnotetext{
* Corresponding author.

E-mail addresses: bueno.luizah@gmail.com (L.H.B. da Silva), amcl@rc.unesp.br (A.M. Costa-Leonardo).
} 
The other studied termite is Cornitermes cumulans (Kollar, 1832), that is a Netropical termite belonging to the Termitidae family, which occurs in Brazil, Paraguay and Argentina (Araújo, 1970). This species is a multiple-piece nesting termite, whose colonies live in a well-define nest separated from the food source (Korb, 2005). It builds mound nests that may reach considerable size and presents large population when compared with those of $C$. brevis.

Corpse management have been studied in termites, but there is no record about this subject in the basal Kalotermitidae family. In the Termitidae family, there are reports of corpse management in Pseudacanthotermes spiniger dealated female that buried corpses of other females for the purpose of nest hygiene (Chouvenc et al., 2012). Laboratory studies of the competition between two Neotropical termitids, C. cumulans and Procornitermes araujoi, showed that, after confrontation, individuals killed during it were used to block tunnels and to deter other species (Jost et al., 2012).

In the present study, we evaluated the corpse management in $C$. brevis and $C$. cumulans under laboratory conditions to verify the behavioural repertoire and the consequent final disposal of termite corpses. We tested cadavers of different origins, which might replicate natural contexts (for example, confrontation interactions between termites that could result in the death of a nestmate or alien). We hypothesized that termites would perform different corpse management according to the origin of the cadaver and the nesting ecology of the species.

\section{Material and methods}

\subsection{Termites}

Ten natural colonies of $C$. brevis were extracted from several pieces of infested furniture collected in different districts of the city of Rio Claro, SP, Brazil $\left(22^{\circ} 24^{\prime} \mathrm{S}, 47^{\circ} 33^{\prime} \mathrm{W}\right)$. Two nests of $C$. cumulans were collected in Rio Claro, SP, Brazil ( $\left.22^{\circ} 23^{\prime} \mathrm{S}, 47^{\circ} 32^{\prime} \mathrm{W}\right)$, transported to the laboratory and maintained at $25 \pm 2{ }^{\circ} \mathrm{C},>80 \%$ relative humidity $(\mathrm{RH})$ in complete darkness. Each nest was provided with water and food ad libitum.

\subsection{Preparation of corpses}

Undertaking responses to corpses of different origins were tested in subcolonies of $C$. brevis and colonies of $C$. cumulans. Termite workers were frozen to death at $-6{ }^{\circ} \mathrm{C}$ for $20 \mathrm{~min}$ and kept in a covered Petri dish at room temperature for $30 \mathrm{~min}$. After this period, the corpses were introduced into the experimental arenas which were used for the development of the bioassays.

\subsection{Experimental set-up}

The experimental arena used with $C$. brevis consisted of a circular excavation ( $35 \mathrm{~mm}$ diameter and $8 \mathrm{~mm}$ depth) in a Pinus sp. wood block $(100 \times 45 \times 25 \mathrm{~mm})$ covered with a glass sheet. A sample from each $C$. brevis colony comprising the primary queen, the primary king, one soldier, pseudergates and nymphs was introduced into this artificial arena (Table 1). After the transference, these subcolonies were acclimatised in the dark for a period of $48 \mathrm{~h}$.

The experimental set-up for $C$. cumulans included a nest chamber connected to an observation arena (Fig. 1). A whole nest of $C$. cumulans was placed in a plastic box $(53 \times 37 \times 34 \mathrm{~cm})$ containing moistened sterilised soil and it was called nest chamber. The observation arena, composed of a plastic container $(21 \times 21 \times 7.5 \mathrm{~cm})$, was connected by a plastic tube $(0.4 \mathrm{~cm}$ internal diameter, $12 \mathrm{~cm}$ length) to the nest chamber and contained four fragments of sterilised sugarcane bagasse as food. Each nest was maintained in laboratory conditions during three weeks for acclimation before the experiments. This proceeding allowed termites to discover the food and to mark their trail with faeces.

\subsection{Bioassays}

To compare the behavioural responses of $C$. brevis and $C$. cumulans towards corpses from different origins, three bioassays were performed, each bioassay based on a different corpse origin as follows: a) intracolonial corpse: cadaver from the same colony; b) intercolonial corpse: cadaver from the same species collected in other colony; and c) interspecific corpse: dead worker of Coptotermes gestroi. We used corpses of cospecific pseudergates and workers in experiments with $C$. brevis and $C$. cumulans, respectively. In each test, the lid or glass sheet was gently removed and one corpse was introduced in the experimental arena, which was then covered to avoid disturbance by airflow. All bioassays were replicated 10 times. The video recording was performed using a videocamera (Sony HDR-CX130 full HD) and started immediately after the corpse introduction. Empirical studies were carried out to determine a 15-minute recording time for bioassays with $C$. brevis and 20-minutes for $C$. cumulans. The bioassays were conducted under red light (methodology of Machida et al., 2001) at $25 \pm 2{ }^{\circ} \mathrm{C}$ with $>$ $80 \%$ RH.

We carried out qualitative observations to define the main categories and behavioural acts exhibited by $C$. brevis towards and near the corpses, which compose the behavioural repertoire of corpse management. The frequency of the following behaviours of $C$. brevis individuals was recorded: antennation, retreat (avoid confrontation), agonism, alarm (oscillatory movement with the whole body), grooming and corpse ingestion. Due to difficulty in differentiating grooming from ingestion, both behaviours were analysed together and their duration was evaluated. Final observations were made $72 \mathrm{~h}$ after the beginning of the experiment and, to quantify the consumption, a point was given to each body part that was consumed. Thus, each of the following parts, if ingested, received a point: antenna (two in total), legs (six in total), abdomen, thorax and damaged head; the maximum total was 11 points per cadaver. The three behavioural bioassays were performed once in each of the ten $C$. brevis subcolonies. Tests in the same subcolony were separated by at least one week.

Experimental tests with $C$. cumulans started when one corpse was placed into the region located between the opening of the connector tube and the food in the observation arena, that is, in the trail of the termites to the food. Each bioassay was replicated five times in both nests of $C$. cumulans. Qualitative observations were used to determine the main categories of behaviour exhibited by $C$. cumulans individuals towards and near the corpse, which composed the behavioural repertoire of corpse management. The frequency of the following behaviours was recorded: antennation, retreat, agonism, grooming, alarm, deposition of faeces, deposition of soil and transport of corpse to the nest.

\subsection{Data analysis}

Data on the frequency of the reported categories of behaviour were compared using a non-parametric Kruskal-Wallis test, followed by $a$ posteriori Student-Newman-Keuls test when necessary. A significance level $(\alpha)$ equal to 0.05 was adopted. The behavioural categories that did not present any record were not submitted to statistical analysis. For comparison of differences between two groups, a Mann-Whitney test was used.

\section{Results}

\subsection{Bioassays with Cryptotermes brevis}

The results showed that a large part of the corpse management repertoire displayed by Cryptotermes brevis was performed by nymphs and pseudergates. Soldiers participated through inspection and agonism. Although the soldiers inspected all the corpses, they performed agonism only towards the intercolonial and interspecific ones. The royal couple 
Table 1

Census of Cryptotermes brevis subcolonies used in behavioural bioassays.

\begin{tabular}{|c|c|c|c|c|c|c|c|c|}
\hline Subcolony & Primary queen & Primary king & Nymphs & Pseudergates & Larvae & Soldiers & Eggs & Total Population \\
\hline 1 & 1 & 1 & 3 & 11 & 0 & 1 & 4 & 17 \\
\hline 2 & 1 & 1 & 6 & 6 & 0 & 1 & 0 & 15 \\
\hline 3 & 1 & 1 & 4 & 8 & 1 & 1 & 2 & 16 \\
\hline 4 & 1 & 1 & 9 & 3 & 1 & 1 & 0 & 16 \\
\hline 5 & 1 & 1 & 5 & 8 & 2 & 1 & 0 & 18 \\
\hline 6 & 1 & 1 & 7 & 6 & 4 & 1 & 0 & 20 \\
\hline 7 & 1 & 1 & 5 & 7 & 4 & 1 & 4 & 19 \\
\hline 8 & 1 & 1 & 5 & 7 & 2 & 1 & 1 & 17 \\
\hline 9 & 1 & 1 & 4 & 6 & 4 & 1 & 0 & 17 \\
\hline 10 & 1 & 1 & 4 & 5 & 2 & 1 & 0 & 14 \\
\hline
\end{tabular}

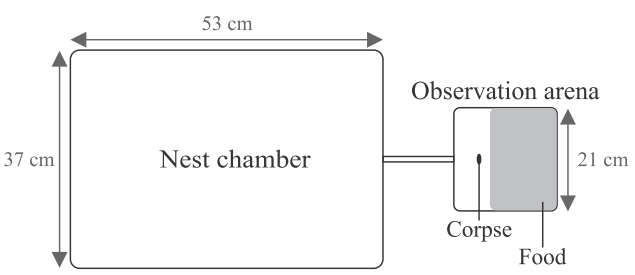

Fig. 1. Experimental set-up for bioassays with Cornitermes cumulans. In each replication, a corpse was introduced in the region between the food and the opening of the connector tube of the experimental arena.

did not participate in corpse management.

All of the corpses tested in the bioassays were consumed by the pseudergates and nymphs, regardless of their origin (Fig. 2). Corpse management performed towards intracolonial corpses started with the inspection of cadavers through antennation, followed by the individuals exhibiting alarm behaviour. In $40 \%$ of the replications with intracolonial corpses, pseudergates and nymphs performed agonism. Only the pseudergates and nymphs eventually cannibalised the corpses.

Corpse management of intercolonial and interspecific corpses also started with antennation by nymphs, pseudergates and soldiers. Some nymphs and pseudergates exhibited retreat after contact with the corpses, others together with the soldiers attacked alien corpses. During this process of corpse management, some individuals from the quoted castes exhibited alarm behaviour. Finally, nymphs and pserdergates ingested the corpses.

Antennation behaviour displayed by $C$. brevis on corpses from different origins did not significantly differ (Kruskal-Wallis test: $H_{2}=2.133, P=0.344$ ). With all corpse types, antennation was the most common behavioural category recorded (mean \pm SE in percentage: $46.9 \pm 5.3 \%$ of all behaviours recorded in bioassays using interspecific corpses, $38.8 \pm 7.1 \%$ with intercolonial corpses and $65.4 \pm 4.5 \%$ with intracolonial corpses). In addition, the alarm behaviour was not significantly different among the different corpses $\left(H_{2}=5.9114, P=0.052\right)$.

Our analysis also revealed that agonistic behaviour towards corpses

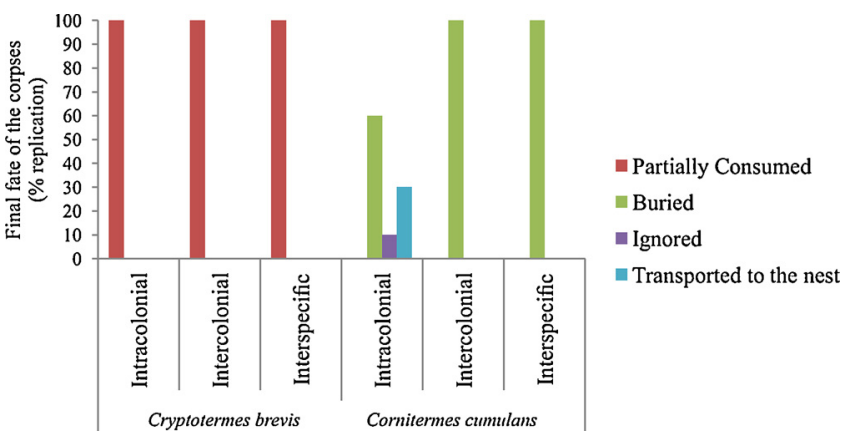

Fig. 2. Final fate of the corpses from different origins in bioassays with Cryptotermes brevis and Cornitermes cumulans. significantly differed between those of intracolonial and intercolonial origin $\left(H_{2}=9.284, P=0.0254\right)$, as well as between intracolonial and interspecific corpses $(P=0.0036)$ (Fig. 3a). The agonistic behaviour was observed in $40 \%$ of replications with intracolonial corpses, in $90 \%$ with intercolonial corpses and $100 \%$ with interspecific corpses. Nymphs and pseudergates did not retreat when coming into contact with intracolonial corpses. Additionally, there was significant difference in the frequency of retreat between intercolonial and interspecific corpses (Mann-Whitney test: $\mathrm{U}=3.477, N 1=N 2=10, P=0.0005$ ) (Fig. 3b). The time spent on grooming or corpse consumption did not differ significantly among corpses from different origins (Kruskal-Wallis test: $\left.H_{2}=3.073, P=0.251\right)$. Final observations of corpses $(72 \mathrm{~h}$ after the beginning of the experiment) showed that the consumption of cadavers significantly differed between intracolonial and interspecific cadavers $\left(H_{2}=8.355, P=0.0068\right)$ and between intercolonial and interspecific cadavers $(P=0.039)$. The data indicated that $C$. brevis had tendency to consume conspecific corpses.

\subsection{Bioassays with Cornitermes cumulans}

Our set-up for $C$. cumulans allowed the corpse to be placed on the foraging trail, consequently only forager individuals found the corpse. Thus, the observations revealed that workers of $C$. cumulans actively participated in the corpse management. They inspected and performed the final corpse disposal, which could be based on three options: corpse transport towards the nest, corpse entombment or avoidance of the corpse (Fig. 2). Whereas, the soldier participation included inspection and agonism of corpses and they guarded the area while workers were entombing the corpse.

Interspecific corpses were covered with soil and faeces by workers of $C$. cumulans. Immediately after the corpse introduction into the experimental arena, workers and soldiers approached and inspected the corpse with their antennae. Several workers exhibited retreat behaviour after contact with the cadaver. However, some workers and soldiers showed agonistic behaviour and other workers groomed the corpse. Approximately $4 \mathrm{~min}$ after introduction of the corpse, a worker deposited the first droplet of faeces on the cadaver. Subsequently, about $5 \mathrm{~min}$ after the beginning of the experiment, some workers started to cover the corpse with soil and faeces. On two occasions, the deposition of food fragments (sugar cane bagasse) on the cadaver was recorded. During the entombment process, workers and soldiers also showed alarm behaviour; this was characterised by an oscillatory movement of the body or the head.

The intercolonial cadavers were submitted to a process similar to that observed with interspecific corpses, which resulted in the corpse entombment. The undertaking responses always started with the inspection of cadavers by workers and soldiers. After the inspection, some workers also groomed the corpse. Following the activities described above (about $3 \mathrm{~min}$ after the introduction of the corpse), a worker deposited the first faeces droplet. Approximately one minute after this event, workers began to cover the corpse intermittently with soil and 

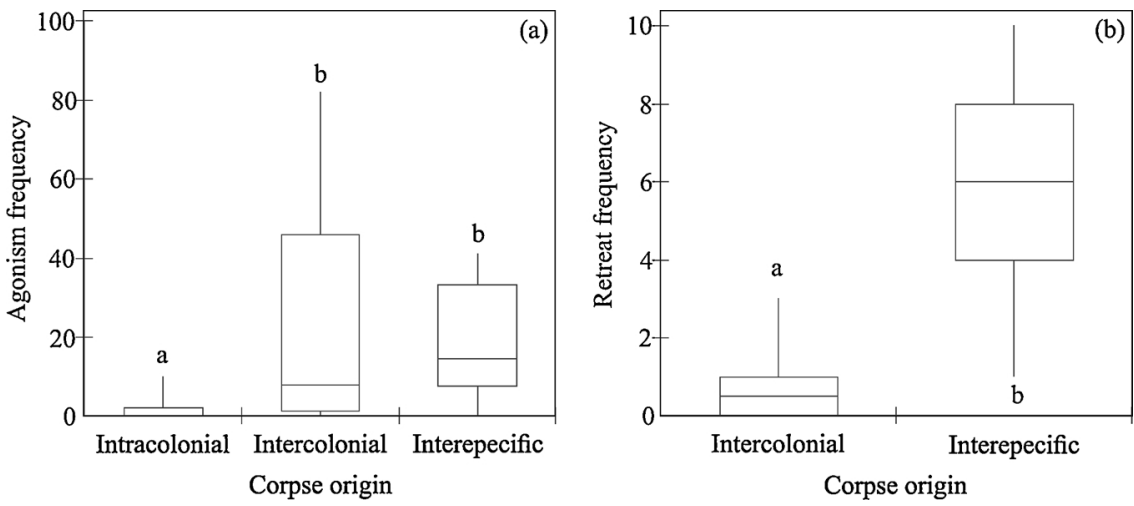

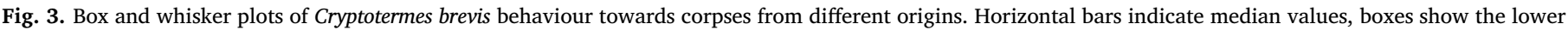
and upper quartiles of the data sets. (a) Agonism behaviour (b) Retreat behaviour. Different letters indicate statistical differences $(P<0.05)$.

faecal material. Throughout the corpse management, some soldiers and workers exhibited alarm behaviour, but this behaviour was more frequent during the corpse covering process.

Workers of C. cumulans performed varied corpse management activities on dead nestmates. In $30 \%$ of the replications, a worker grasped the corpse using its mandibles and transported it to the nest chamber. In $10 \%$ of replications, workers groomed the corpse and then abandoned it. In $60 \%$ of replications, workers covered the corpses with soil and faeces after had groomed them (Fig. 2).

Antennation behaviour performed by $C$. cumulans workers and soldiers was not significantly different among treatments (Kruskal-Wallis test: $H_{2}=5.7089, P=0.0576$ ). In contrast, agonistic behaviour significantly differed among corpses from different origins (Kruskal-Wallis test: $H_{2}=24.075, P<0.001$ ) (Fig. 4a). Workers never attacked nestmates corpses, only soldiers did it. Workers also did not retreat after contact with intracolonial corpses. The display of this behaviour towards corpses significantly differed between those of intercolonial and interspecific origins (Mann-Whitney test: $U=3.5907, N 1=N 2=10$, $P=0.0003$ ) (Fig. 4b). Additionally, time spent on grooming the corpses differed only between interspecific and intercolonial cadavers (Kruskal-Wallis test: $H_{2}=6.5213, P=0.0111$ ). Furthermore, the data showed that there was a wide variation in time invested in grooming nestmate corpses among the replications.

Corpse marking with faeces droplets was statistically similar among the cadavers of different origins $\left(H_{2}=5.4474, P=0.0656\right)$. Intracolonial corpses that were transported into the nest or abandoned were not marked with faeces. To perform the faeces deposition, the worker rotated its body, pointed the end of the abdomen and expelled a faeces droplet on an undefined area of the cadaver.

The soil deposition behaviour significantly differed among all treatments $\left(H_{2}=19.311, P=0.0001\right)$. Interspecific corpses received 3

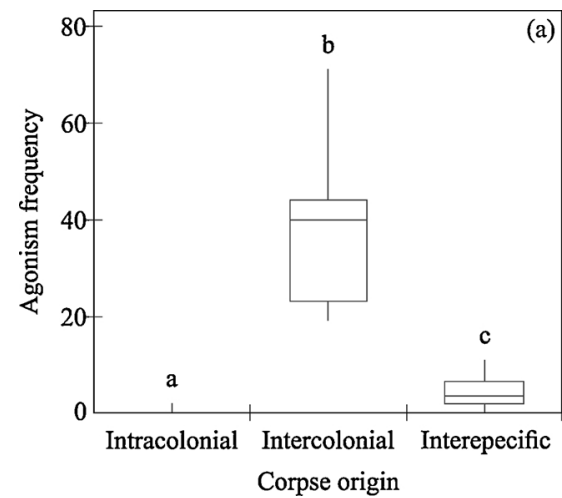

times more soil deposition than intercolonial corpses and 10 times more than intracolonial cadavers. Alarm behaviour displayed by workers and soldiers differed mainly between the presence of intercolonial and interspecific corpses $\left(H_{2}=7.685, P=0.0061\right)$. Additionally, workers exhibited a repeated longitudinal movement in the anterior-posterior direction of their bodies and the soldiers performed a head-banging movement towards corpses from all origins.

\section{Discussion}

The royal couple of $C$. brevis subcolonies did not participate in corpse management, even when the cadaver was an alien or a nestmate. The corpse management in mature colonies of social insects, as well as other maintenance and hygiene behaviours, is generally carried out by the worker caste (Wilson, 1971; Wilson et al., 1958). However, in incipient termite colonies, the royal couple performs tasks to ensure their own survival and of their progeny. Laboratory experiments with incipient pleometrotic colonies of $P$. spiniger (Termitidae) showed that corpses of dealated female were groomed and buried (Chouvenc et al., 2012). Nevertheless, in established colonies with available workers, the royal couple does not perform the corpse management, as observed in C. brevis.

C. brevis nymphs and pseudergates performed the final corpse disposal, and the soldiers participated in the process by discriminating between cadavers of different origins and being aggressive toward corpses from another colony and another species. There is no description in the literature of corpse management by pseudergates or other castes in Kalotermitidae.

Another comparison is that $C$. cumulans soldiers inspected the cadavers, displayed agonistic behaviour and guarded the area while workers were entombing the corpse. The same result was observed in

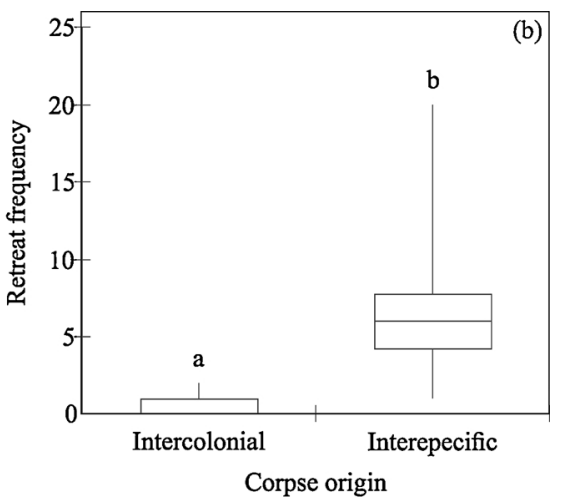

Fig. 4. Box and whisker plots of Cornitermes cumulans behaviour towards corpses from different origins. Horizontal bars indicate median values, boxes show the lower and upper quartiles of the data sets. (a) Agonism behaviour (b) Retreat behaviour. Different letters indicate statistical differences $(P<0.05)$. 
colonies of the Reticulitermes flavipes (Rhinotermitidae) subterranean termite, in which the soldiers guarded the entrance of the experimental arena while the workers performed the management of the intracolonial corpses (Sun et al., 2013). According to the authors, these soldiers occasionally inspected the conspecific corpses with their antennae, but did not exhibit agonistic responses, although they attacked congeneric termite corpses. Therefore, soldiers do not directly participate in the corpse management, but are able to identify the origin of dead individuals and provide defence to the workers while they perform the corpse disposal. The behaviour of guarding the foraging area during the entombment, as performed by $C$. cumulans, seems to be adaptive for a multiple-piece nesting termite.

The behavioural repertoire of corpse management performed by $C$. brevis and $C$. cumulans was initiated with antennation. This behaviour was also observed in bees, wasps, ants and in other termites (Neoh et al., 2012; Sun et al., 2013; Visscher, 1988). To start the corpse management it is imperative that the colony members distinguish dead individuals from living ones (Sun and Zhou, 2013). Ulyshen and Shelton (2012) reported that in Reticulitermes virginicus termite the recognition of corpses involves the synergism between chemical (oleic acid) and tactile cues (shape and texture). The action of fatty acids as chemical cues of cadavers had been described in ants, cockroaches and bees (Rollo et al., 1994; Visscher, 1983; Wilson et al., 1958). The stimuli are detected by the insects through chemosensory sensilla on the antennae. According to Chouvenc et al. (2012), in dealated females of $P$. spiniger the combination of several chemical components elicited undertaking responses, including various fatty acids, indole and phenol. In the present study, $C$. brevis and $C$. cumulans performed corpse management immediately after the introduction of cadavers from different origins, which suggests that the cues to dead recognition were present in all tested cadavers.

Nymphs, pseudergates and soldiers of $C$. brevis, and workers and soldiers of $C$. cumulans exhibited alarm behaviour towards corpses of different origins. Additionally, this behaviour was more frequent during the entombment process in C. cumulans. According to Neoh et al. (2012), the Microcerotermes crassus and Globitermes sulphureus termites also exhibited alarm responses during the corpse management. The same behaviour displayed by workers and soldiers of $R$. flavipes towards congeneric corpses seemed to facilitate the recruitment of other workers and soldiers (Sun et al., 2013). C. cumulans may have also recruited individuals to perform the collective activity of covering the corpses with soil and faeces.

Pseudergates and nymphs of $C$. brevis and workers of $C$. cumulans exhibited retreat behaviour, especially in the presence of corpses from another colony or different species. Neoh et al. (2012) described that in G. sulphureus termite workers inspected nestmate corpses and, afterwards, avoided them. Foraging workers of Coptotermes gestroi changed their tunnelling pattern when they found soldiers corpses of Heterotermes tenuis in order to avoid confrontation and to isolate dead termites (Lima and Costa-Leonardo, 2012). Additionally, workers of Reticulitermes hesperus avoided areas where there were termites which had been killed by insecticides (Smith and Rust, 1991). According to Dukas (2001), Apis mellifera avoided flowers where there were corpses of nestmates or the extract of their cadavers. This author infers that the activity of avoiding places where there were corpses and, thus, the preference for sites with safe characteristics is a strategy to prevent predation. Therefore, the retreat behaviour of $C$. brevis and C. cumulans seems to be a strategy to avoid contamination, especially by alien corpses.

The corpse management exhibited by nymphs and pseudergates of C. brevis resulted in the consumption of termite cadavers regardless of their origin. According to Potrikus and Breznak (1981), cannibalism and necrophagy promote the recycling of nutrients. In addition, cannibalism is considered a consequence of stress, such as nitrogen deficiency (Collins, 1983; Lee and Wood, 1971). Thus, the consumption of dead individuals may occasionally contribute to a greater survival of the colony through nitrogen intake. However, several authors report that the primary function of cannibalism is not the recycling of proteins, but the hygiene of the nest and this is reinforced by observations that few species kill and consume nestmates (Collins, 1983; Lima and CostaLeonardo, 2007). Despite these conflicting views, the consumption of cadavers can help the survival of the $C$. brevis colony, because these termites obtain water from food and corpse consumption can aid in the transfer of water to the active individuals in the nest.

Some studies also showed that the consumption of the corpses is a hygiene strategy, because it destroys the source of pathogens. When termites ingest this material, they inhibit the development of entomopathogens due to the antimicrobial action of their guts. This was observed in R. flavipes, in which the inhibition of Metarhizium anisopliae fungal development was due to fungistatic action of the termite digestive tract (Chouvenc et al., 2009b). According to Rosengaus and Traniello (2001), the Zootermopsis angusticollis dampwood termite consumed nestmates contaminated with the fungus $M$. anisopliae, indicating that contamination with pathogens did not prevent cannibalism (Rosengaus and Traniello, 2001).

Workers of $C$. cumulans displayed the same corpse management towards intercolonial and interspecific cadavers, which consisted of grooming and entombment of the corpses. This same response was described by Sun et al. (2013) for R. flavipes towards corpses of congeneric $R$. virginicus termite, which were covered with nest soil, faeces and chewed mulch. The use of faecal material and soil from the nest promotes an important antifungalaction (Chouvenc and Su, 2012; Rosengaus et al., 1998a).

Furthermore, corpse burial can be a defence mechanism, since cadavers can obstruct galleries by creating barriers (Li et al., 2010). According to the authors, corpses resulting from agonistic interactions between $C$. gestroi and C. formosanus termites were buried, blocking tunnels that were not subsequently opened. Sealing tunnels can prevent agonistic encounters and future mortality, besides defining boundaries between adjacent termite colonies.

Dealated females of $P$. spiniger groomed corpses of other females and then buried them (Chouvenc et al., 2012). According to Lamberty et al. (2001), the saliva of these females contains peptides with antibiotic and antifungal properties, suggesting that the grooming activity associated with the physical isolation of corpses is an important part of the strategy for preventing dispersal of opportunistic pathogens among colony members. Neves and Alves (2000) observed that the grooming performed by $C$. cumulans workers removed conidia of the Beauveria bassiana and $M$. anisopliae fungi from the nestmate cuticles. The grooming behaviour, along with the antifungal activity of the termite guts, provides an effective individual and also inter-individual defence against fungi (Chouvenc et al., 2009a). Allogrooming has an important function in the control of disease in termites (Rosengaus et al., 1998b). Accordingly, the grooming behaviour exhibited by C. cumulans can promote the removal of pathogens in the corpse before its physical isolation in the foraging area.

C. cumulans showed different strategies for disposal of dead nestmates: The cadavers were buried at the foraging site, abandoned after being groomed or transported into the nest. Sun et al. (2013) reported that the $R$. flavipes also transported intracolonial corpses into the nest and proposed that these corpses were probably cannibalised later. In contrast, Torales (1982) found corpses inside the nests of $C$. cumulans which were whole or with missing thorax and abdomen. In the latter case, the heads were clustered with soil grains and faeces inside chambers of a nest in the laboratory. According to the author, these chambers, called a "cemetery", were coated with abundant faecal material and their openings were often sealed with heads of workers and soldiers. Likewise, Neoh et al. (2012) also found carcasses confined in a sealed cavity in nests of the $M$. crassus.

The workers of $C$. cumulans marked corpses of different origins with faecal material before covering them with soil. According to Torales (1982), C. cumulans begins the construction process by depositing a 
droplet of faecal material. This same material is used between successive soil deposits. Other termite species, such as the subterranean $C$. gestroi and Heterotermes spp., also mark the surface used for transit and food with faecal pellets (Fontes and Araújo, 1999). Faecal marking of foraging trails of the Nasutitermes corniger termite has a chemical signalling function, which, through pheromonal activity, helps the orientation of foraging individuals (Silva, 2008; Stuart, 1969). Faecal marking probably has a similar function in C. cumulans.

The corpse management repertoires of $C$. brevis and $C$. cumulans have some similar behaviors, which are related to the cadaver recognition: antennation, retreat, alarm and agonism. However, those species perform different final disposals.

C. brevis consumed the corpses. One-piece nesting termites do not leave the nest to forage, so to find a corpse, this must be introduced inside the nest, which turns impracticable to ignore it, as it would maintain the threat within the nest. It is also impossible for them to bury corpses, for they live in the wood. Thus, corpse consumption is a strategy of hygiene and also defense, as shown in response to alien corpses. Furthermore, this consumption allows nitrogen and water intake, which benefits the colony. Likewise, corpse management repertoire of $C$. cumulans has behaviours that may be adaptive for its type of nest. Multiple-piece nests are more elaborated and possess several chambers, some of them internally coated with faecal material (Torales, 1982). Therefore, it is possible to confine the corpses in sealed cavities of the nest, or it may isolate the corpse by entombment within the feeding area, which may be a strategy of defending it.

The present study shows that one-piece nesting termite, as $C$. brevis, exhibits a simplified corpse management repertoire, which ends with the cadaver consumption, regardless its origin. Conversely, a multiplepiece nesting species, as $C$. cumulans, presents a diverse behavioural repertoire, which may include recruitment of individuals to perform corpse entombment, with a variation in time spent and amount of soil according to the cadaver origin; avoidance of some intracolonial cadavers; or individually transporting some of the intracolonial corpses into the nest, which shows the complexity of this last approaches.

\section{Conflict of interest}

The authors declare that they have no conflict of interest.

\section{Acknowledgements}

This study was supported by $\mathrm{CNPq}$ (Conselho Nacional de Desenvolvimento Científico e Tecnológico (Proc. No. 305539/2014-0) and CAPES (Coordenação de Aperfeiçoamento de Pessoal de Nível Superior). We thank Célia RR Camargo-Dietrich for technical assistance.

\section{References}

Rosengaus, R.B., Guldin, M.R., Traniello, J.F.A., 1998a. Inhibitory effect of termite fecal pellets on fungal spore germination. J. Chem. Ecol. 24, 1697-1706. https://doi.org/ 10.1023/A:1020872729671.

Araújo, R.L., 1970. Termites of the neotropical region. In: Krishna, K., Weesner, F.M. (Eds.), Biology of Termites. Academic Press, New York pp. 527-576.

Rosengaus, R.B., Maxmen, A.B., Coates, L.E., Traniello, J.F.A., 1998b. Disease resistance: a benefit of sociality in the dampwood termite Zootermopsis angusticollis (Isoptera: Termopsidae). Behav. Ecol. Sociobiol. 44, 125-134. https://doi.org/10.1007/ s002650050523.

Brazolini, S., Fernandes, J.L.G., Lopes, G.A.C., Monteiro, M.B.B., Zenid, G.J., 2001 Biodeteriorização de madeira em edificações. IPT, São Paulo.

Choe, D.-H., Millar, J.G., Rust, M.K., 2009. Chemical signals associated with life inhibit necrophoresis in Argentine ants. Proc. Natl. Acad. Sci. U. S. A. 106, 8251-8255. https://doi.org/10.1073/pnas.0901270106.

Chouvenc, T., Su, N.-Y., 2012. When subterranean termites challenge the rules of fungal epizootics. PLoS One 7, 28-31. https://doi.org/10.1371/journal.pone.0034484.

Chouvenc, T., Su, N.Y., Robert, A., 2009a. Cellular encapsulation in the eastern subterranean termite, Reticulitermes flavipes (Isoptera), against infection by the entomopathogenic fungus Metarhizium anisopliae. J. Invertebr. Pathol. 101, 234-241. https://doi.org/10.1016/j.jip.2009.05.008.
Chouvenc, T., Su, N.Y., Robert, A., 2009b. Inhibition of Metarhizium anisopliae in the alimentary tract of the eastern subterranean termite Reticulitermes flavipes. J. Invertebr. Pathol. 101 (2), 130-136. https://doi.org/10.1016/j.jip.2009.04.005.

Chouvenc, T., Robert, A., Sémon, E., Bordereau, C., 2012. Burial behaviour by dealates of the termite Pseudacanthotermes spiniger (Termitidae, Macrotermitinae) induced by chemical signals from termite corpses. Insectes Soc. 59, 119-125. https://doi.org/10. 1007/s00040-011-0197-3.

Collins, N.M., 1983. The utilization of nitrogen resources by termites (Isoptera). In: Lee, J.A., Mcneill, S., Rorison, I.H. (Eds.), Nitrogen as an Ecological Factor. Oxford University Press, Oxford pp. 381-412.

Cremer, S., Armitage, S.A.O., Schmid-Hempel, P., 2007. Social immunity. Curr. Biol. 17, 693-702. https://doi.org/10.1016/j.cub.2007.06.008.

Driessen, G.J.J., Van Raalte, A.T., De Bruyn, G.J., 1984. Cannibalism in the red wood ant, Formica polyctena (Hymenoptera: formicidae). Oecologia 63, 13-22.

Dukas, R., 2001. Effects of perceived danger on flower choice by bees. Ecol. Lett. 4, 327-333. https://doi.org/10.1046/j.1461-0248.2001.00228.x.

Fontes, L.R., Araújo, R.L., 1999. Os cupins. In: Mariconi, F.A.M. (Ed.), Insetos e Outros Invasores de Residências. FEALQ, Piracicaba pp. 35-90.

Haskins, C.P., Haskins, E.F., 1974. Notes on necrophoric behavior in the. Psyche (Stuttg.) 81, 258-267.

Howard, D.F., Tschinkel, W.R., 1976. Aspects of necrophoric behavior in the red imported fire ant, Solenopsis invicta. Behaviour 56, 157-180.

Jost, C., Haifig, I., de Camargo-Dietrich, C.R.R., Costa-Leonardo, A.M., 2012. A comparative tunnelling network approach to assess interspecific competition effects in termites. Insectes Soc. 59, 369-379. https://doi.org/10.1007/s00040-012-0229-7.

Korb, J., 2005. Termites. Curr. Biol. 17, R995-R999. https://doi.org/10.1016/j.cub.2007. 10.033.

Lamberty, M., Zachary, D., Lanot, R., Bordereau, C., Robert, A., Hoffmann, J.A., Bulet, P., 2001. Insect immunity. Constitutive expression of a cysteine-rich antifungal and a linear antibacterial peptide in a termite insect. J. Biol. Chem. 276, 4085-4092. https://doi.org/10.1074/jbc.M002998200.

Lee, K.E., Wood, T.G., 1971. Termites and Soils. Academic Press, London.

Li, H.-F., Yang, R.-L., Su, N.-Y., 2010. Interspecific Competition and Territory Defense Mechanisms of Coptotermes formosanus and Coptotermes gestroi (Isoptera: Rhinotermitidae). Environ. Entomol. 39, 1601-1607. https://doi.org/10.1603/ EN09262.

Lima, J.T., Costa-Leonardo, A.M., 2007. Tipos de alimentação categorias de recursos alimentares explorados pelos cupins. Biota Neotrop. 7, 1-8.

Lima, J.T., Costa-Leonardo, A.M., 2012. Tunnelling behaviour of the Asian subterranean termite in heterogeneous soils: presence of cues in the foraging area. Anim. Behav. 83, 1269-1278. https://doi.org/10.1016/j.anbehav.2012.02.020.

López-Riquelme, G.O., Fanjul-Moles, M.L., 2013. The funeral ways of social insects. Social strategies for corpse disposal. Trends Entomol. 9, 71-128.

Machida, M., Kitade, O., Miura, T., Matsumoto, T., 2001. Nitrogen recycling through proctodeal trophallaxis in the Japanese damp-wood termite Hodotermopsis japonica (Isoptera,Termopsidae). Insectes Soc. 48, 52-56. https://doi.org/10.1007/ PL00001745.

Neoh, K.B., Yeap, B.K., Tsunoda, K., Yoshimura, T., Lee, C.Y., 2012. Do termites avoid carcasses? Behavioral responses depend on the nature of the carcasses. PLoS One 7. https://doi.org/10.1371/journal.pone.0036375.

Neves, P.J., Alves, S.B., 2000. Selection of Beauveria bassiana(Bals.) Vuill. andMetarhizium anisopliae (Metsch.) Sorok. strains for control of Cornitermes cumulans (Kollar). Braz. Arch. Biol. Technol. 43. https://doi.org/10.1590/S1516-89132000000400004.

Potrikus, C.J., Breznak, J.A., 1981. Gut bacteria recycle uric acid nitrogen in termites: a strategy for nutrient conservation. Proc. Natl. Acad. Sci. U. S. A. 78, 4601-4605. https://doi.org/10.1073/pnas.78.7.4601.

Renucci, M., Tirard, A., Provost, E., 2011. Complex undertaking behavior in Temnothorax lichtensteini ant colonies: from corpse-burying behavior to necrophoric behavior. Insectes Soc. 58, 9-16. https://doi.org/10.1007/s00040-010-0109-y.

Rollo, C.D., Czvzewska, E., Borden, J.H., 1994. Fatty acid necromones for cockroaches. Naturwissenschaften 81, 409-410. https://doi.org/10.1007/BF01132695.

Rosengaus, R.B., Traniello, J.F.A., 2001. Disease susceptibility and the adaptive nature of colony demography in the dampwood termite Zootermopsis angusticollis. Behav. Ecol. Sociobiol. 50, 546-556. https://doi.org/10.1007/s002650100394.

Scheffrahn, R.H., Křeček, J., Ripa, R., Luppichini, P., 2009. Endemic origin and vast anthropogenic dispersal of the West Indian drywood termite. Biol. Invasions 11 787-799. https://doi.org/10.1007/s10530-008-9293-3.

Silva, V.S.G., 2008. Comportamento de forrageamento de Nasutitermes corniger (Motschlsky) (Isoptera:Termitidae) e sua ocorrência em áreas urbanas. Campos dos Goytacazes Universidade Estadual do Norte Fluminense Darcy Ribeiro.

Smith, J.L., Rust, M.K., 1991. Factors Affecting the Tunneling Behavior of the Western Subterranean Termite, Reticulitermes Hesperus Banks 128. U S For. Serv. Gen. Tech. Rep. Psw, pp. 28-33.

Stuart, A.M., 1969. Social behavior and communication. Biology of Termites. https://doi. org/10.1016/B978-0-12-395529-6.50011-8. pp. 193-232.

Sun, Q., Haynes, K.F., Zhou, X., 2013. Differential undertaking response of a lower termite to congeneric and conspecific corpses. Sci. Rep. 3, 1-8. https://doi.org/10. 1038/srep01650.

Sun, Q., Zhou, X., 2013. Corpse management in social insects. Int. J. Biol. Sci. 9, 313-321. https://doi.org/10.7150/ijbs.5781.

Torales, G.J., 1982. Contribucion al conocimiento de las termites de Argentina (Pcia. De. Corrientes)Cornitermes cumulans (Isoptera: Termitidae). Facena 5, 97-133.

Ulyshen, M.D., Shelton, T.G., 2012. Evidence of cue synergism in termite corpse response behavior. Naturwissenschaften 99, 89-93. https://doi.org/10.1007/s00114-0110871-3.

Visscher, P.K., 1983. The honey bee way of death: necrophoric behaviour in Apis mellifera 
colonies. Anim. Behav. 31, 1070-1076. https://doi.org/10.1016/S0003-3472(83) 80014-1.

Visscher, P.K., 1988. Undertaker specialists in honey bee colonies. In: Jeanne, R.L. (Ed.), Interindividual Behavioral Variability in Social Insects. Westview Press, Boulder pp. 359-383.

Wilson, E.O., 1971. The Insect Societies. Cambridge Belknap Press of Cambridge University Press.
Wilson, E.O., 1985. The sociogenesis of insect colonies. Science 228 (80-), 1489-1495. Wilson, E.O., Durlach, N.I., Roth, L.M., 1958. Chemical releaser of necrophoric behavior in ants. Psyche (New York) 65, 108-114. https://doi.org/10.1155/1958/69391.

Yao, M., Rosenfeld, J., Attridge, S., Sidhu, S., Aksenov, V., Rollo, C.D., 2009. The ancient chemistry of avoiding risks of predation and disease. Evol. Biol. 36, 267-281. https:// doi.org/10.1007/s11692-009-9069-4. 